\title{
Deformability and Osmotic Fragility of Phenylhydrazine-injected Rat Erythrocytes Fractionated by Percoll Density-gradients
}

\author{
Takashi NAGASAwA \\ Department of Physiology, Osaka City University, Medical School, \\ Abeno-ku, Osaka, 545 Japan
}

\begin{abstract}
Red blood cells (RBCs) from phenylhydrazine-injected rats were separated according to their specific densities by centrifugation on a polyvinyl-pyrrolidone-coated colloidal silica matrix (Percoll). The deformability and osmotic fragility of fractionated RBCs were measured by ektacytometer and coil planet centrifuge, respectively. Immature reticulocytes, the least dense RBC subpopulation, were less deformable and osmotically more resistant than normal RBCs. Heinz-body containing RBCs, the most dense subpopulation, showed reduced deformability and increased osmotic fragility. These findings suggest that young reticulocytes have increased membrane stiffness and that Heinz-body containing RBCs have an extremely rigid membrane.

Key Words: red cell deformability, ektacytometry, osmotic fragility, coil planet centrifuge, Percoll.
\end{abstract}

The deformation of red cells is an important cellular phenomenon in blood circulation (LeBLOND et al., 1971; Bessis and MoHANDAS, 1975b). The survival of red cells is critically dependent upon their ability to maintain normal flexibility which is regulated by three major factors: 1 ) the viscoelastic properties of the membrane; 2) the geometry of the cell, including the ratio of cell surface area to cell volume; and 3) the viscosity of the intracellular hemoglobin milieu (MOHANDAS et al., 1979). The preparation of blood samples highly enriched in reticulocytes and the measurement of their deformability and osmotic fragility are problems of great interest in studying the physiological membrane function. In this study, erythropoietically stimulated animals served those purposes and enriched fractions of reticulocytes were obtained by discontinuous isotonic-isoosmotic Percoll gradients. Their deformability and osmotic fragility were studied using ektacytometer and coil planet centrifuge.

\section{MATERIALS AND METHODS}

Erythropoietic stimulation. Wistar rats (male, $150 \mathrm{~g}$ ) were injected twice

Received for publication July 13, 1981

長澤貴志 
with phenylhydrazine hydrochloride $(5 \mathrm{mg} / 100 \mathrm{~g}$ body weight), once on Day 1 and once on Day 2, and blood was drawn by cardiac puncture in anesthetized rats 3 days after the last injection.

Cell separation by Percoll density-gradients. Subpopulations of red cells of phenylhydrazine-injected rats were separated on the basis of differences in density. Whole blood was fractionated on discontinuous gradients of polyvinylpyrrolidone-coated colloidal silica matrix (Percoll; Pharmacia Fine Chemicals AB, Uppsala, Sweden). A stock solution of isotonic Percoll was prepared by the addition of 1 part $10 \times$ Rabinowitz's calcium- and magnesium-free phosphatebuffered saline (RABINOwITZ, 1965) to 9 parts Percoll, and this was diluted in Rabinowitz's buffer saline to prepare several solutions with specific density values ranging from 1.068 to $1.124 \mathrm{~g} / \mathrm{ml}$. In a typical separation, $0.5 \mathrm{ml}$ volumes of Percoll media were carefully overlayered in a centrifuge tube with Pasteur pipettes at $4^{\circ} \mathrm{C}$ and $0.5 \mathrm{ml}$ of whole blood was layered onto the discontinuous gradients, the tube being centrifuged at $800 \mathrm{~g}$ for $20 \mathrm{~min}$ at $4^{\circ} \mathrm{C}$. The cell fractions were carefully aspirated and washed by centrifugation 3 times with an excess of phosphate-buffered saline.

Measurement of red cell deformability. Red cell deformability was evaluated using a diffractometric technique (Ektacytometry) reported by Bessis et al. (BESSIS and MoHANDAS, 1975a; Sutera et al., 1975). The ektacytometer consists of a concentric cylinder viscometer in which the red cells are subjected to well-defined shear stresses. The diameter of the inner cylinder is $50 \mathrm{~mm}$, and the gap between the inner and outer cylinders is $0.5 \mathrm{~mm}$. To obtain the diffraction patterns, a helium-neon laser source is used, and with the aid of two prisms, the beam is made to traverse the gap between the inner and outer transparent cylinders. The transformation of the diffraction pattern from a circle to an ellipse is related to the deformability of the individual cells in suspension. Fifty $\mu \mathrm{l}$ of blood suspended at $50 \%$ in phosphate-buffered saline was mixed with $10 \mathrm{ml}$ of $15 \%$ dextran T40 (average molecular weight 40,000, Pharmacia Fine Chemical AB) dissolved in phosphate-buffered saline $\left(0.12 \mathrm{M} \mathrm{NaCl}, 0.020 \mathrm{M} \mathrm{Na}_{2} \mathrm{HPO}_{4}, 0.005 \mathrm{M} \mathrm{KH}_{2} \mathrm{PO}_{4}\right.$, 290 mOsm, pH 7.4) to obtain a dilute red cell suspension. During an experiment, the gap between the inner and outer cylinders was filled with this suspension. The outer cylinder of the viscometer was rotated at 0 to $200 \mathrm{rpm}$ to avoid mechanical hemolysis. The diffraction patterns at various values of the applied stress were photographed. To analyze the data, the inner dimension of the first ring in the diffraction pattern was measured from the negative, and the deformability index (D.I.) was calculated using the formula D.I. $=(L-W) /(L+W)$, where $L$ is the measured vertical dimension of the diffraction pattern and $W$ is the horizontal dimension. The applied shear stress was calculated in $\mathrm{dyn} / \mathrm{cm}^{2}$ using the formula $\tau_{\mathrm{s}}=2 \pi \mu N R / 60 h$, where $\mu$ is the suspending media viscosity, $N$ is the $\mathrm{rpm}$ of the outer cylinder, $R$ is the radius of the inner cylinder $(2.5 \mathrm{~cm})$ and $h$ is the gap between the inner and outer cylinders $(0.05 \mathrm{~cm})$. 
Dynamic measurement of osmotic fragility of red cells. The osmotic fragility of red cells was measured by the coil planet centrifuge system as described elsewhere (ITO et al., 1966; NAGASAwA et al., 1976). Ten $\mu$ l of a red cell sample suspended at $50 \%$ in phosphate-buffered saline was used to measure the osmotic fragility of red cells. The osmotic fragility was measured at $37^{\circ} \mathrm{C}$ and hemolytic patterns were recorded on a scanning photodensitometer.

Staining. For reticulocyte counts, small drops of concentrated blood samples were incubated for $3 \mathrm{~min}$ on a slide glass with new methylene blue (NMB) at room temperature, and smears were made. A minimum of 500 cells was counted.

\section{RESULTS}

\section{Stimulation of erythropoiesis}

Hematocrit changes and blood reticulocyte values in rats after injections of phenylhydrazine hydrochloride are shown in Fig. 1. Before the injection of phenylhydrazine, rats had a hematocrit of $39 \%$. During the next 2 days, as anemia developed and progressed, the hematocrit dropped to a low value of $22 \%$. From Days 4 and 5 the hematocrit rose gradually to $33 \%$ and the percentage of reticulocytes increased as the bone marrow responded to the anemic stress. This increase can be attributed to the shifting of reticulocytes from the bone marrow pool to the circulating blood to compensate for the anemia. The blood (Days 5) was used for the following experiments.

\section{Red cell separation by Percoll density-gradients}

Fractionation of RBCs by isopycnic centrifugation on discontinuous Percoll gradients resulted in 9 fractions being formed (Fig. 2). White cells and platelets were layered over the density $1.076 \mathrm{~g} / \mathrm{ml}$. Subpopulation A $(1.076-1.080 \mathrm{~g} / \mathrm{ml})$, subpopulation B $(1.092-1.100 \mathrm{~g} / \mathrm{ml})$, and subpopulation $\mathrm{C}(>1.116 \mathrm{~g} / \mathrm{ml})$ were
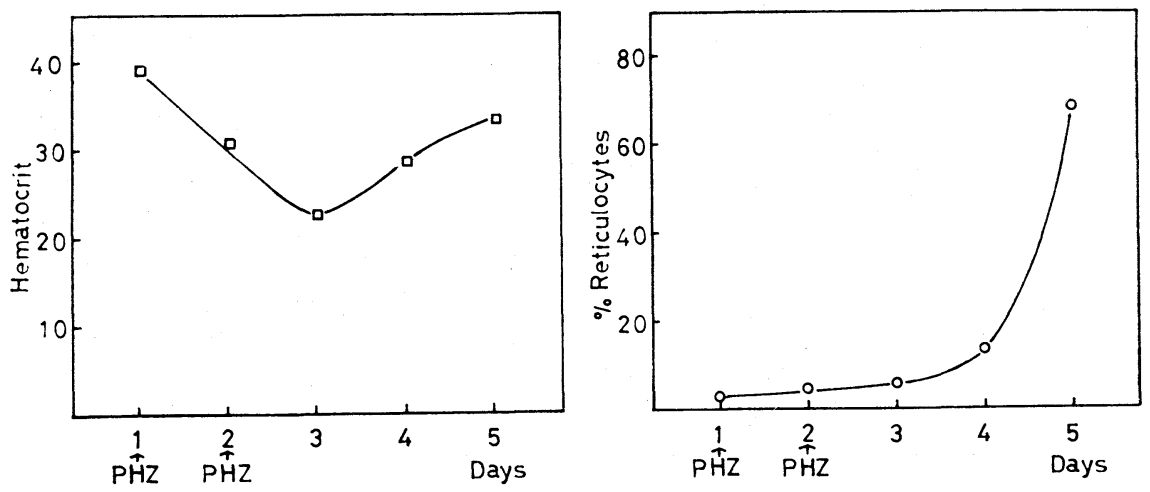

Fig. 1. Hematocrit values $(\square)$ and blood reticulocytes values $(O)$ as a function of time following two injections of phenylhydrazine hydrochloride on Days 1 and 2. 


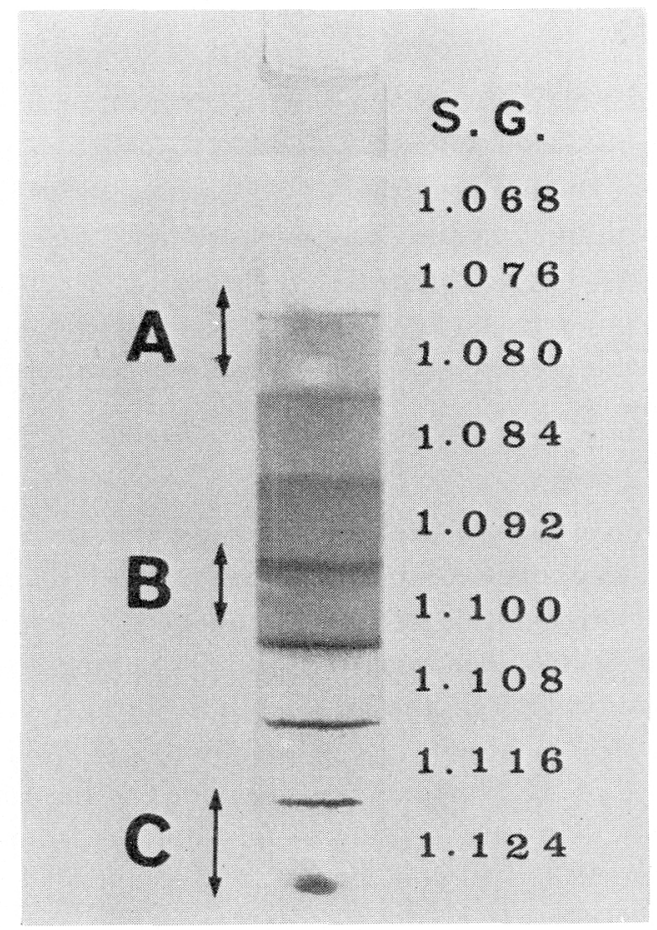

Fig. 2. Typical separation of whole blood of phenylhydrazine-injected rat on discontinuous isotonic-isoosmotic Percoll density-gradients ranging from 1.068 to $1.124 \mathrm{~g} / \mathrm{ml}$. Subpopulation $\mathrm{A}, \mathrm{B}$, and $\mathrm{C}$ served to measure the deformability and osmotic fragility of erythrocytes.

obtained as shown in Fig. 2. Subclassification of the NMB-staining was performed with respect to the Heilmeyer-Westhäuser stages of maturation: stages I-II, heavily staining, young; stages III-IV, lightly staining, mature. Unseparated whole blood consisted of $68 \%$ of reticulocytes (young and mature reticulocytes) and $26 \%$ of Heinz-body containing red cells (Fig. 3-1). Subpopulation A contained $95-100 \%$ reticulocytes (85-95\% young, 0-12\% mature reticulocytes) and no Heinz-body containing red cells (Fig. 3-2). Subpopulation B contained 90 $93 \%$ reticulocytes (30-37\% young, 55-63\% mature reticulocytes) and 3-8\% Heinz-body containing red cells (Fig. 3-3). Subpopulation C contained 97-100\% Heinz-body containing red cells and no reticulocytes (Fig. 3-4). By Percoll density-gradients young reticulocytes and Heinz-body containing red cells were highly purified in subpopulation A and C, respectively.

\section{Red cell deformability by ektacytometry}

Figure 4 shows the diffraction patterns of deformed cells obtained under the action of $125 \mathrm{dyn} / \mathrm{cm}^{2}$ with normal rat red cells and phenylhydrazine-injected rat 


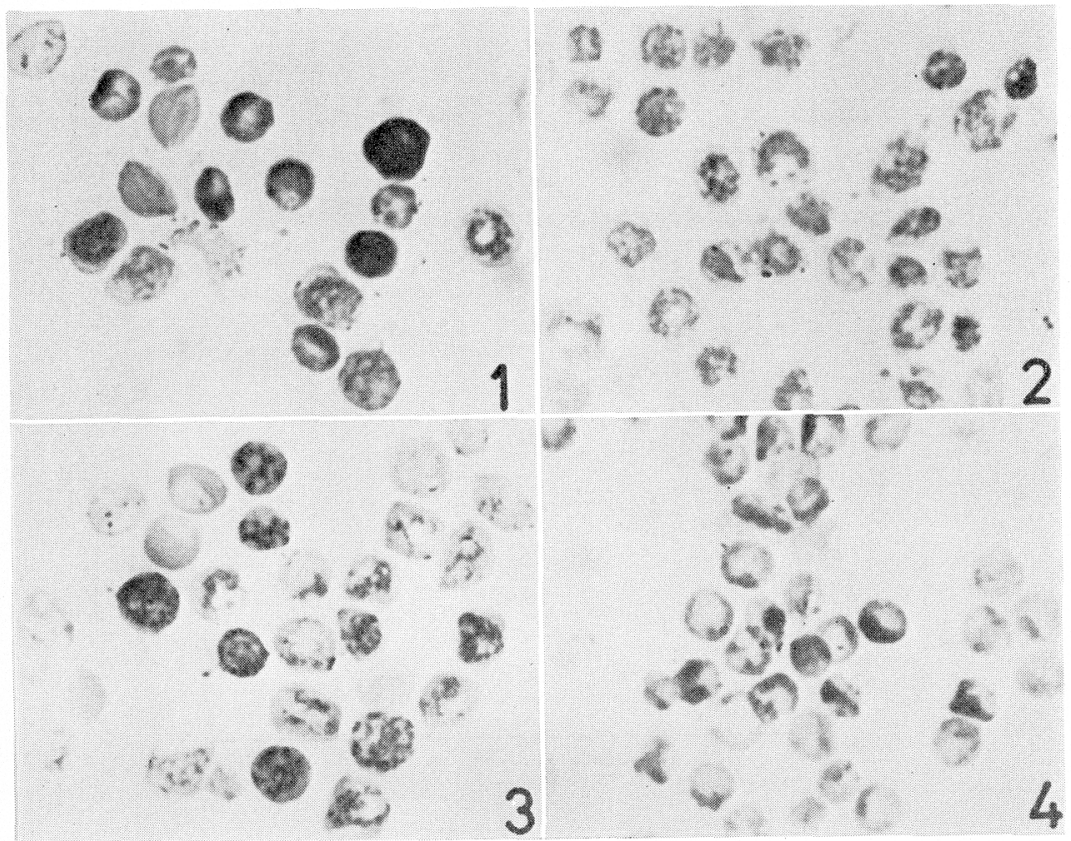

Fig. 3. Micrographs of new methylene blue-stained cells. (1) Unfractionated whole blood of phenylhydrazine-injected rat, (2) purified heavily stained immature reticulocytes in subpopulation A, (3) stained cells in subpopulation B, and (4) Heinz-body containing red cells enriched in subpopulation $\mathrm{C}$.

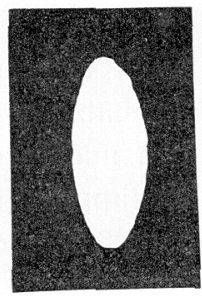

a

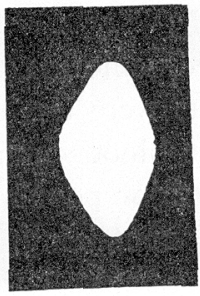

b

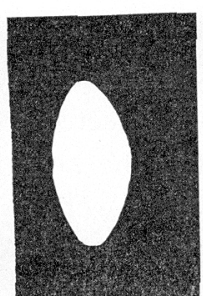

C

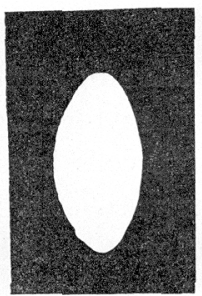

d

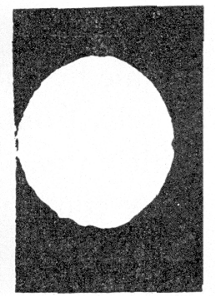

e

Fig. 4. Diffraction patterns photographed at an applied stress of $125 \mathrm{dyn} / \mathrm{cm}^{2}$. (a) Normal rat red cells, (b) whole blood of phenylhydrazine-injected rat, (c) young reticulocytes in subpopulation A $(1.076-1.080 \mathrm{~g} / \mathrm{ml})$ fractionated by Percoll discontinuous density-gradients, (d) subpopulation B $(1.092-1.100 \mathrm{~g} / \mathrm{ml})$, and (e) subpopulation C $(>1.116 \mathrm{~g} / \mathrm{ml})$ containing Heinz-body red cells.

red cells. In the diffraction pattern of Fig. $4 \mathrm{~b}$, the elliptical diffraction pattern given by the deformable cells is superimposed on the circular diffraction pattern given by the undeformable Heinz-body containing red cells.

Figure 5 shows the deformability of red cells from a normal rat and a rat

Vol. 32, No. 2, 1982 


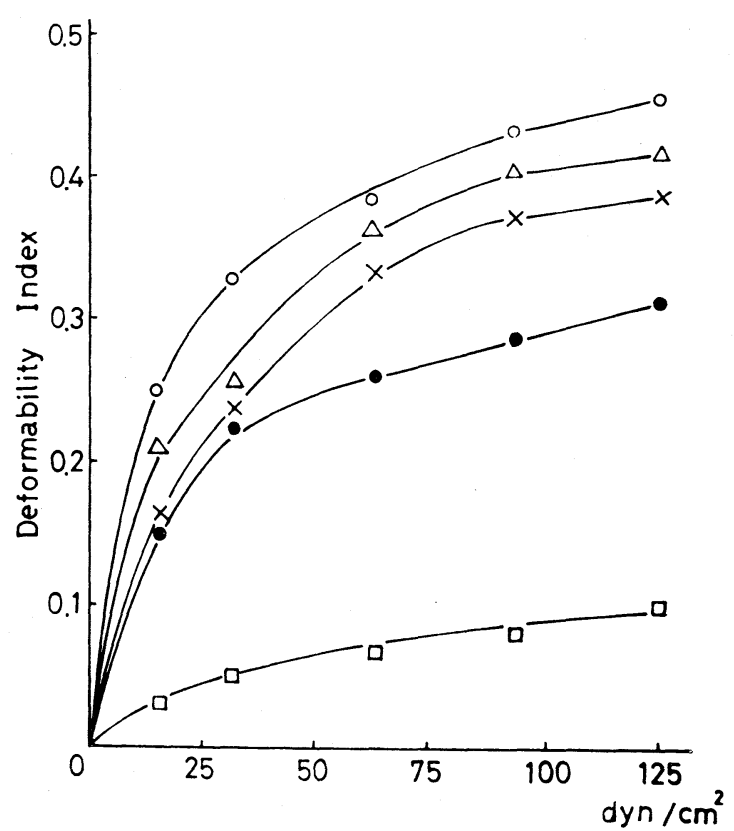

Fig. 5. Deformability curves at applied shear stresses for normal red cells $(O)$; whole blood of phenylhydrazine-injected rat $(\bullet)$; immature reticulocytes separated in subpopulation A $(\triangle)$; red cells of subpopulation $\mathrm{B}(\times)$; and Heinz-body containing red cells in subpopulation $\mathrm{C}(\square)$. Deformability index is represented by the measured value of the length minus the width of the diffraction pattern $(L-W)$ divided by the sum $(L+W)$.

made anemic by injection of phenylhydrazine hydrochloride (Day 5), respectively. The red cells from phenylhydrazine-injected rats were less deformable as compared with normal red cells because the anemic blood contained undeformable Heinz-body containing red cells which were a major population (approximately $97 \%$ ) in subpopulation C. Subpopulation A containing young reticulocytes (approximately $98 \%$ ) was deformable, but not completely deformable as compared with normal red cells.

\section{Osmotic fragility of red cells by coil planet centrifuge}

The hemolysis of normal rat red cells began at $116 \pm 3 \mathrm{mOsm}$, was completed at $70 \pm 2 \mathrm{mOsm}$ and peaked at $95 \pm 4 \mathrm{mOsm}$. Whole blood of phenylhydrazineinjected rats had a biphasic hemolytic pattern as shown in Fig. 6B, suggesting that this consisted of two populations of red cells; osmotically resistant and fragile red cells. Subpopulation A (Fig. 7A) which contained the major population of young reticulocytes was osmotically resistant in comparison with normal red cells. Subpopulation B (Fig. 7B) which consisted of a major population of young and mature reticulocytes and a minor population of Heinz-body containing red cells 


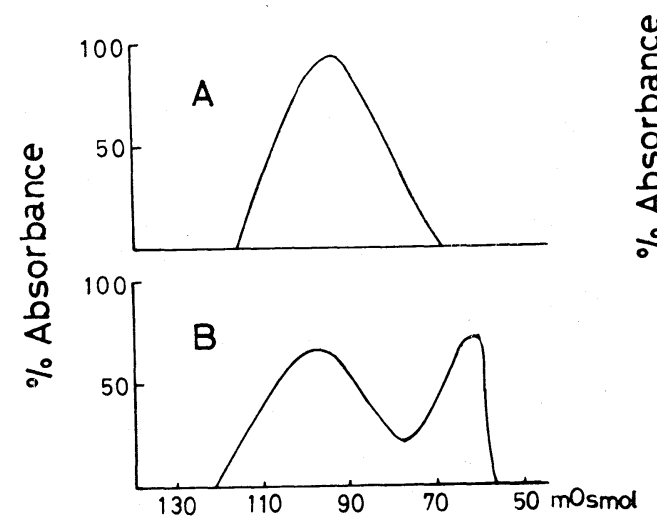

Fig. 6.
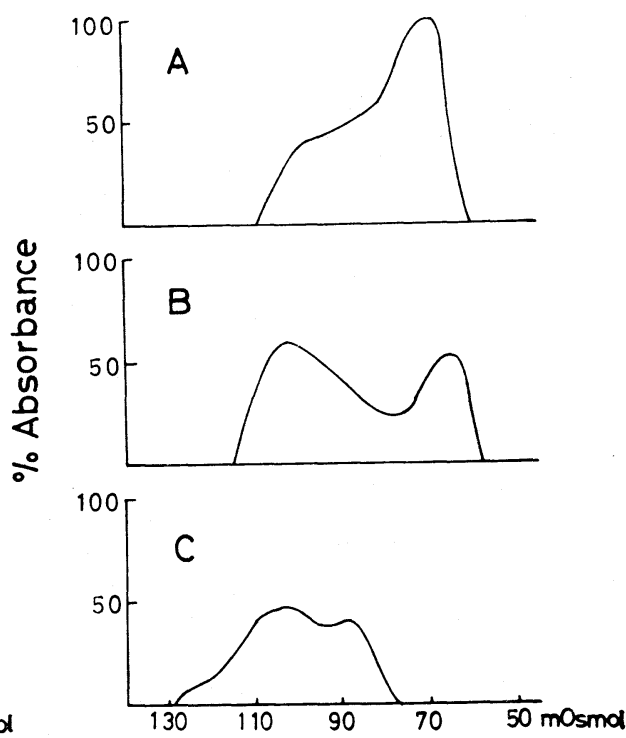

Fig. 7 .

Fig. 6. Osmotic fragility curves of red cells from normal rat (A) and phenylhydrazineinjected rat (B) measured by the coil planet centrifuge system.

Fig. 7. Osmotic fragility curves of red cells of subpopulation A (A), subpopulation B (B), and subpopulation $\mathrm{C}(\mathrm{C})$ which were separated by Percoll discontinuous density-gradients.

had a hemolytic curve resembling that of unseparated whole blood. Subpopulation C (Fig. 7C) which consisted of a majority of Heinz-body containing red cells showed increased osmotic fragility.

\section{DISCUSSION}

Many techniques for the separation of cells and organelles have been reported (Leif and Vinograd, 1964; Danon and Marikovsky, 1964; Boyd et al., 1967; Pertoft and BACK, 1968; Vettore et al., 1980; Pertoft et al., 1978). Desirable features of a density-gradient method for cell separation are easy and fast preparation of the gradient system, isotonicity, low viscosity, physiological $\mathrm{pH}$ at a suitable specific gravity, and absence of toxicity for the cells or red cell agglutination. Percoll fulfills these desiderata in the isopycnic separation of cells and subcellular materials (Pertoft et al., 1978). As shown in Fig. 2, discontinuous density-gradients of Percoll were edsily prepared and highly purified young reticulocytes were obtained in subpopulation A (Fig. 3-2), and Heinz-body containing red cells in subpopulation C (Fig. 3-4).

The deformability of red cells has been shown to be an important factor in 
reducing the bulk viscosity of blood flowing through larger vessels; it plays an indirect but crucial role in the rheology of blood circulation in large blood vessels. Deformability of red cells has been measured using various techniques including the monitoring of deformation induced by fluid stresses on erythrocytes stuck to a flat surface (НоснмUтн et al., 1973), aspiration of red cells into micropipettes (WeED et al., 1969), measurement of red cell filtration time (MuRPHY, 1967), resistive pulse spectroscopy (MEL and YEE, 1975), and ektacytometry (BESSIS and MoHANDAS, 1975a). Cellular deformability in the diffractometric technique is evaluated by measuring the increase in cellular dimensions under applied fluid shear stress conditions. By comparing the cellular lengths of normal cells with those of pathological cells under identical experimental conditions, the cellular deformability differences can be obtained. In the present experiment, the blood sample of anemic rats with double populations (deformable and undeformable) showed a superimposed image of circular and elliptical diffraction patterns (Fig. $4 \mathrm{~b}$ ), suggesting that this was composed of deformable (Fig. 4c and d) and undeformable (Fig. 4e) red cells.

With the Parpart osmotic fragility method, rat red cells start hemolyzing at $155 \mathrm{mOsm}$ and are completely hemolyzed at $125 \mathrm{mOsm}$. It is not clear why, with the coil planet centrifuge method, this range is shifted down to $116-70 \mathrm{mOsM}$, however, such a discrepancy may be attributed to differences in the time of exposure of the red cells to the osmotic gradient.

MoHANDAS and BoISFLeUry (1978) reported changes in deformability of red cells from anemic rat after the injection of antiserum and indicated that the mature reticulocytes in the blood appeared to be as deformable as normal mature red cells. The data presented here indicated that fractionated young reticulocytes (subpopulation A) were slightly less deformable and osmotically more resistant than mature red cells although young reticulocytes have decreased internal viscosity of intracellular hemoglobin milieu, suggesting that immature reticulocytes possess increased rigidity of the membrane. The mechanism regulating intrinsic viscoelasticity of young reticulocyte membrane is unknown. However, it is suggested that a reversible sol-gel transformation occurs at the membrane-interior interface of the reticulocyte, depending on a critical ratio between $\mathrm{Ca}^{2+}, \mathrm{Mg}^{2+}$, and ATP inside the cell (LEBLOND et al., 1971). In a recent study (SHOHET and GREENQUIST, 1978), it has been reported that membrane protein phosphorylation, in particular the phosphorylation of spectrin, is a modulator of cell shape and deformability.

Heinz-bodies are irregularly shaped bodies, varying in size from barely perceptible dots to spheres $2 \mu \mathrm{m}$ in diameter, and consist of precipitated, denaturated hemoglobin which is attached to the inner surface of red cell membrane. From the data of decreased deformability and increased osmotic fragility of Heinz-body containing red cells, it is tempting to postulate that the modification of membrane structure induced by phenylhydrazine rigidified the membrane of red cells and 
that early hemolysis of red cells occurred without the occurrence of stretching to the point of normal membrane rupture.

The author is indebted to Dr. Marcel C. Bessis and Dr. Claude Feo (Institut de Pathologie Cellulaire, Université de Paris) for permitting the use of the ektacytometer.

\section{REFERENCES}

Bessis, M. and MoHANDAs, N. (1975a) A diffractometric method for the measurement of cellular deformability. Blood Cells, 1: 307-313.

Bessis, M. and Mohandas, N. (1975b) Deformability of normal, shape-altered and pathological red cells. Blood Cells, 1: 315-321.

Boyd, E. M., THOMAs, D. R., and Horton, B. F. (1967) The quantities of various minor hemoglobin components in old and young human red blood cells. Clin. Chim. Acta, 16: 333-341.

Danon, D. and Marikovsky, Y. (1964) Determination of density distribution of red cell population. J. Lab. Clin. Med., 64: 668-674.

Hochmuth, R. M., Mohandas, N., and Blackshear, P. L. (1973) Measurement of the elastic modulus for the red cell membrane using a fluid mechanical technique. Biophys. J., 13: $747-762$.

Ito, Y., Weinstein, M. A., Harada, R., Kimura, E., and NunogaKi, K. (1966) The coil planet centrifuge. Nature, 212: 985-987.

Leblond, P. F., LaCelle, P. L., and Weed, R. I. (1971) Cellular deformability: A possible determinant of the normal release of maturing erythrocytes from the bone marrow. Blood, 37: 40-46.

LeIF, R. C. and Vinograd, J. (1964) The distribution of buyant density of human erythrocytes in bovine albumin solutions. Proc. Natl. Acad. Sci. U.S.A., 51: 520-528.

MeL, H. C. and YeE, J. P. (1975) Erythrocyte size and deformability studies by resistive pulse spectroscopy. Blood Cells, 1: 391-399.

Mohandas, N. and Boisfleury, A. (1978) Antibody-induced spherocytic anemia. I. Changes in red cell deformability. In: Red Cell Rheology, ed. by Bessis, M., Shонет, S. B., and MoHandAs, N. Springer-Verlag, Berlin, pp. 187-196.

Mohandas, N., Phillips, W. M., and Bessis, M. (1979) Red blood cell deformability and hemolytic anemias. Semin. Hematol., 16: 95-114.

MuRPHY, J. R. (1967) The influence of $\mathrm{pH}$ and temperature on some physical properties of normal erythrocytes from patients with hereditary spherocytosis. J. Lab. Clin. Med., 69: 758-774.

Nagasawa, T., Sudo, K., Nishi, N., Sarashi, A., and Kimura, E. (1976) Graphic analysis of osmotic fragility of erythrocytes. Tohoku J. Exp. Med., 120: 277-285.

Pertoft, H. and BACK, O. (1968) Separation of various blood cells in colloidal silica-polyvinylpyrrolidone gradients. Exp. Cell Res., 50: 355-368.

Pertoft, H., Laurent, T. C., Lass, T., and Kagedal, L. (1978) Density gradient prepared from colloidal silica particles coated by polyvinylpyrrolidone (Percoll). Anal. Biochem., 88: 271-282.

RABINOWITZ, Y. (1965) Adherence and separation of leukemic cells on glass bead columns. Blood, 26: 100-103.

Shohet, S. B. and Greenquist, A. C. (1978) Possible roles for membrane protein phosphorylation in the control of erythrocyte shape. In: Red Cell Rheology, ed. by Bessis, M., SHoHET, S. B., and Mohandas, N. Springer-Verlag, Berlin, pp. 115-133.

Sutera, S., MehrJardi, M., and Mohandas, N. (1975) Deformation of erythrocytes under 
shear. Blood Cells, 1: 369-374.

Vettore, L., Concetta de Matteis, M., and Zampini, P. (1980) A new density gradient system for the separation of human red blood cells. Am. J. Hematol., 8: 291-297.

Weed, R. I., LaCelle, P. L., and Merrill, E. M. (1969) Metabolic dependence of red cell deformability. J. Clin. Invest., 48: 795-809. 